\title{
Association between Beta3-Adrenergic Receptor Trp64Arg Polymorphism and Fat Preference in Healthy Young Japanese Women
}

\author{
Kei Watanabe, ${ }^{1}$ Guang Hong, ${ }^{2}$ Kanako Tominami, ${ }^{1}$ Satoshi Izumi, ${ }^{1}$ Yohei Hayashi ${ }^{3,4}$ \\ and Tada-aki Kudo ${ }^{1}$ \\ ${ }^{1}$ Division of Oral Physiology, Tohoku University Graduate School of Dentistry, Sendai, Miyagi, Japan \\ ${ }^{2}$ Liaison Center for Innovative Dentistry, Tohoku University Graduate School of Dentistry, Sendai, Miyagi, Japan \\ ${ }^{3}$ Cell Resource Center for Biomedical Research, Institute of Development, Aging and Cancer, Tohoku University, \\ Sendai, Miyagi, Japan \\ ${ }^{4}$ Graduate School of Life Sciences, Tohoku University, Sendai, Miyagi, Japan
}

\begin{abstract}
Beta3-adrenergic receptor (ADRB3) is a mediator of catecholamine-stimulated lipolysis in humans. The Trp64Arg polymorphism with T/C transition in the ADRB3 gene has been considered to reduce lipolysis and metabolic expenditure. Here, we investigated the hitherto unknown role of the Trp64Arg substitution on food preference among healthy young adults (mean age, 24.3; $n=53$, including 25 men). Preference toward four food types (bitter, sour, salty, or sweet) and greasy (high-fat) foods was examined using a selfreported questionnaire. There was no noticeable sex-difference in food preference. Incidentally, only among female subjects, the genotype frequencies of the Trp64Arg polymorphism were in accordance with the Hardy-Weinberg equilibrium. Consequently, female subjects were divided into two groups for further analyses: 18 subjects with TT genotype (Trp64Trp) (wild-type group) and 10 subjects with TC genotype (Trp64Arg) (heterozygous group). No significant difference was observed in preference for four food types between the groups. However, when sweet foods were divided into high-fat and low-fat subgroups, food preference for high-fat sweet foods in heterozygous group was significantly higher than that in wild-type group. Moreover, when subjects were divided into two classes based on preference for greasy foods (like, $n=16$ or dislike, $n=12)$, the preference degree in heterozygous group who liked high-fat foods $(n=5)$ was significantly higher than that in wild-type group $(n=11)$, suggesting that the Trp64Arg substitution might genetically enhance high-fat food preference. Thus, understanding the relationship between ADRB3 Trp64Arg substitution and fat preference will be valuable for obesity prevention.
\end{abstract}

Keywords: beta3-adrenergic receptor; fat metabolism; food preference; high-fat foods; single nucleotide polymorphism Tohoku J. Exp. Med., 2019 July, 248 (3), 181-192. (C) 2019 Tohoku University Medical Press

\section{Introduction}

Obesity, which is related to a variety of health complications such as hyperlipidemia and cancer (Hubert et al. 1983), has become a worldwide epidemic (Kovesdy et al. 2017). Excess energy intake is a major contributor to obesity (Pang et al. 2016). However, because eating is an instinctive behavior that is necessary to maintain homeostasis and because it confers mental benefits including relaxation and satisfaction (Murakami et al. 2017), it is difficult to maintain caloric restriction for a long time in individuals. Thus, it is important to clarify factors that are associated with the regulatory mechanisms of food preference (which drives food intake and energy balance) to develop novel dietary treatments that can be easily followed by individu- als.

Food intake regulation is principally controlled by two interacting pathways in the brain, specifically, one pathway that controls metabolic homeostasis and the other that determines food reward (Morton et al. 2006; True et al. 2018). Further, oral sensory perception also has a role in food preference (Martínez-Ruiz et al. 2014). For example, humans can genetically perceive five basic taste qualities via the taste buds in the oral cavity, including sweet (signaling the presence of carbohydrates), salty (governing the consumption of salts), sour (signaling the existence of dietary acids), bitter (protecting against the intake of toxic foods), and umami (helping to identify protein-rich foods) (Janssen and Depoortere 2013; Satoh-Kuriwada et al. 2014).

Received March 25, 2019; revised and accepted July 8, 2019. Published online July 26, 2019; doi: 10.1620/tjem.248.181.

Correspondence: Tada-aki Kudo, Division of Oral Physiology, Tohoku University Graduate School of Dentistry, 4-1 Seiryo-machi, Aoba-ku, Sendai, Miyagi 980-8575, Japan.

e-mail: tkudo@ tohoku.ac.jp 
Whereas humans prefer and enjoy the taste of fatty foods, they cannot clearly perceive the fat taste (Drewnowski and Greenwood 1983; Mizushige et al. 2007; Fushiki 2014). Recently, the taste of free fatty acids (degradation products of triacylglycerides), but not triacylglycerides themselves, was considered a possible novel basic taste (Mattes 2011; Keast and Costanzo 2015). Free fatty acid receptor candidates have already been identified, including $\mathrm{G}$ protein-coupled receptor 120 , in the taste receptor cells on the tongue surface (Cartoni et al. 2010; DiPatrizio 2014). Regarding fat preference, the ingestion of dietary oils such as corn oil (which contains oleic acid and other free fatty acids) has a strong reward effect on the mouse brain, and the involvement of dopaminergic pathways in the nervous system has been suggested to mediate this effect (Imaizumi et al. 2000; Yoneda et al. 2007; Adachi et al. 2013). In this context, several lines have suggested that fatty acid taste sensitivity is related to the consumption of fatty food (Stewart et al. 2010, 2011) or other habits of eating such as satiety after the ingestion of food (Stewart and Keast 2012; Asano et al. 2016; Costanzo et al. 2017). This suggests the presence of unknown modulatory mechanisms underlying fat taste perception, which are mediated by fatty acid taste sensitivity. In addition, it is possible that the mechanism through which dietary fat is sensed in the oral cavity might be associated with fat preference and thus eating habits.

Obesity is also induced by an interaction between environmental and genetic factors (Rosenbaum et al. 1997; de Luis et al. 2008). Among many gene variants in humans, single nucleotide polymorphisms (SNPs, pronounced "snips"), comprise the most common type of genetic variation. Because white adipose tissue plays a key role in regulating energy metabolism, genes preferentially expressed in this tissue have been the focus of research regarding inherited markers associated with obesity (Yoshida and Sakane 1999). One such genetic variant, the focus of the present study, is the tryptophan/arginine change at codon 64 (Trp64Arg, a SNP with a T/C missense mutation in the 190th position of the beta3-adrenergic receptor (ADRB3) gene, from TGG to CGG) in the ADRB3 protein (reference SNP number: rs4994). Human ADRB3 is composed of a single 408-amino-acid long peptide chain that belongs to the $G$ protein-coupled receptor superfamily, along with the beta 1 and beta 2 subtypes, which is characterized by seven transmembrane domains of 22-28 amino acids. The 64th amino acid (Trp) is located in the first intracellular loop of ADRB3, which is crucial for both the movement and effector function of this protein (Strosberg 1997; Li et al. 2018). ADRB3 is a key mediator of catecholamine-stimulated lipolysis (the hydrolysis of triacylglycerides into fatty acids and glycerol), which is required for energy production in the body (Thomas et al. 2000; de Luis et al. 2008). Thus, the Trp64Arg variant of ADRB3 can cause abnormal protein conformational changes that impair the function of this adrenergic receptor itself, and these alternations are associ- ated with decreased metabolic expenditure with reduced lipolysis, as well as visceral obesity (a risk factor for the development of dyslipidemia and non-insulin-dependent diabetes mellitus (NIDDM)) (Kim-Motoyama et al. 1997; Sipiläinen et al. 1997; Tchernof et al. 1999; Yoshida and Sakane 1999; Li et al. 2018). This ADRB3 Trp64Arg (T/C) polymorphism is included in a group of so-called thrifty SNPs.

In many populations, the mutant allelic frequency (or the number of individual alleles of a certain type divided by the total number of all alleles at a genetic locus in a given population) was found to be $4.9-13 \%$ (Yoshida and Sakane, 1999). For example, the mutant allelic frequency in Europeans is $8 \%$; however, Mongoloids including Inuits, Pima Indians, and Japanese show relatively higher allelic frequencies, reaching more than $30 \%$ in Pima Indians and approaching 20\% in Japanese (Yoshida and Sakane 1999; Bjerregaard et al. 2003; Takeuchi et al. 2012).

However, the association between the $A D R B 3$ Trp64Arg (T/C) polymorphism and dietary fat preference, which might be related to increased calorie intake, is still largely unknown, despite the important role of this receptor in fat metabolism. Therefore, in the present study, we investigated the effect of the ADRB3 Trp64Arg (T/C) substitution on food preference using data obtained from genotyping and self-reported questionnaires from healthy young Japanese adults.

\section{Materials and Methods}

Study subjects

The study subjects were restricted to non-smoking, non-medicated young Japanese adults ranging from 20 to 38 years of age, of good health condition when they participated in the testing. The age and race were limited to acquire a homogenous subject group concerning these factors and accordingly diminish the effect of these factors on food preferences and other conditions of health. Study subjects were restricted to non-smoking, non-medicated individuals because smoking and medications can influence the normal physiological functions of both the stomatognathic system (including the taste sensing system) and the central nervous system (Tanaka et al. 2018). Sixty-two young adults participated as candidate subjects via open recruitment. Nine candidate subjects were excluded from subsequent data analysis because they did not complete all the tests or did not match the selection criteria in the present study. The remaining data acquired from the 53 young adults (mean age, $24.3 \pm 1.5$ years; range, 20-38) were analyzed.

Study outline

Participants as candidate subjects visited the laboratory room at the Tohoku University Graduate School of Dentistry and answered a self-reported questionnaire, which was prepared to collect information regarding their lifestyles, health status, and habits of eating including various taste preferences. The subjects participated in tests including the genotyping of $A D R B 3$ Trp64Arg (T/C) polymorphisms and an evaluation of basic characteristics. Subject weight, height, body mass index (BMI), and body fat percentage (the total mass of fat divided by total body mass, multiplied by 100) were also mea- 
sured with body composition monitors (Inner Scan 50 or BC-314; Tanita, Tokyo, Japan) and a handcrafted stadiometer for the present study.

All of the experiments in the present study were performed in accordance with the Declaration of Helsinki and the institutional guidelines. We acquired ethics approval to conduct the study from the Ethics Committee of Tohoku University Graduate School of Dentistry. Written informed consent was obtained from all subjects prior to participation.

\section{DNA extraction and genotyping of ADRB3 polymorphism}

To determine the genotypes (TT, TC, or CC) of the ADRB3 Trp64Arg (T/C) polymorphism, a buccal swab from each subject was collected using a sterile cotton swab (Tomy Works, Sakai, Japan). Then, subsequent genotyping was outsourced to EBS (Hiroshima, Japan). In detail, genomic DNA from each subject was extracted from the swab sample with the MagMAX DNA Multi-Sample Ultra Kit (ThermoFisher Scientific, Paisley, UK) and the KingFisher Flex Purification System (ThermoFisher Scientific) in accordance with the manufacturer's instructions. Genotyping was performed by polymerase chain reaction (PCR) with the confronting two-pair primers (PCR-CTPP) method using the KAPA2G Robust PCR Kit (Kapa Biosystems, Wilmington, MA, USA), according to the manufacturer's instructions. Only one subject harboring homozygous mutations of the Arg64 alleles of ADRB3 (genotype: CC) was detected with the aforementioned method among the subjects $(n=53)$ in the present study.

\section{Determination of taste preference}

Basic taste preference was determined using the self-reported questionnaire that was based on a report by Omori (2013); namely, the participants were requested to provide the ratings of tastants (bitter, sour, salty, or sweet foods) on a scale of 1-5, as follows: scale 1 , dislike very much; scale 2, dislike moderately; scale 3, neither like nor dislike; scale 4, like moderately; and scale 5, like very much (Omori 2013; Asano et al. 2016). Six sweet foods included in the questionnaire for the present study were further classified into two subgroups in accordance with the Standard Tables of Food Composition in Japan 2015 (http://fooddb.mext.go.jp/) that describes the fat content contained in each food as follows: (a) high-fat sweet foods (ice cream, chocolate, and strawberry sponge cake [Japanese style shortcake]) with fat contents of 8.0-12.0 g/100 g, 34.1-39.5 $\mathrm{g} / 100 \mathrm{~g}$, and $13.8 \mathrm{~g} / 100 \mathrm{~g}$, respectively, and (b) low-fat sweet foods (yokan [azuki-bean jelly], manju [a Japanese traditional cake, such as a steamed bean-jam bun], and candy with fat contents of $0.2 \mathrm{~g} / 100 \mathrm{~g}$, $0.2-2.1 \mathrm{~g} / 100 \mathrm{~g}$, and $0 \mathrm{~g} / 100 \mathrm{~g}$, respectively. The participants were also requested to rate their degree of greasy (high-fat) food preference on a scale of 1-4, which was previously employed (Asano et al. 2016).

\section{Statistical analysis}

All data are presented as the mean \pm standard deviation unless otherwise stated. Statistical analysis was performed with the statistical package JSTAT for Windows, version 6.8 (Sato, Japan). Statistical differences among group means were identified using appropriate tests as indicated. The chi-square test was used to compare frequencies. For each test, significance was defined as $P<0.05$.

\section{Results}

A summary of the general characteristics of the study subject is shown in Table 1. Subject ages ranged from 20 to 38. BMIs ranged from 17.1 to $28.2 \mathrm{~kg} / \mathrm{m}^{2}$. No significant difference was found in the average BMI between male and female subjects.

To evaluate the relationship between sex differences and basic taste preferences (bitter, sour, salty, and sweet), we compared the subgroups of male and female subjects using data from the prepared self-reported questionnaires of the present study. As shown in Table 2, an analysis of the preference degree of each tastant (such as ice cream, salted salmon, lemon, and parsley) resulted in no significant difference in preference for each tastant between the two sex groups $(P>0.05)$. Moreover, the average extent of preference for each basic tastant was also not significantly different based on sex $(P>0.05$; Fig. 1). Similar results were also observed for low-fat and high-fat sweet foods (Fig. 1).

The genotype of the ADRB3 Trp64Arg (T/C) polymorphism was determined in each subject. As indicated in Table 3, of 25 male subjects, $21(84.0 \%)$ were homozygous (TT), three (12.0\%) were heterozygous (TC), and one $(4.0 \%)$ was homozygous for the variant allele (CC). In addition, of 28 female subjects, 18 (64.3\%) were homozygous (TT) and $10(35.7 \%)$ were heterozygous (TC). Incidentally, only in female subjects, no significant difference was detected between the observed genotype frequencies and the frequencies predicted by the Hardy-Weinberg

Table 1. General characteristics of subjects

\begin{tabular}{|c|c|c|c|c|c|c|c|c|c|c|}
\hline & \multicolumn{3}{|c|}{$\begin{array}{c}\text { All } \\
\text { (Japanese, } n=53 \text { ) }\end{array}$} & \multicolumn{3}{|c|}{$\begin{array}{c}\text { Men } \\
(n=25)\end{array}$} & \multicolumn{3}{|c|}{$\begin{array}{l}\text { Women } \\
(n=28)\end{array}$} & \multirow[t]{2}{*}{$P$ value $\#$} \\
\hline & Mean & SD & Range & Mean & SD & Range & Mean & SD & Range & \\
\hline Age (year) & 24.3 & 1.5 & $20-38$ & 25.2 & 4.2 & $20-38$ & 23.5 & 3.1 & $20-32$ & 0.0883 \\
\hline Height (cm) & 167.2 & 8.9 & $151.1-187.0$ & 174.5 & 5.9 & $165.0-187.0$ & 160.7 & 5.4 & 151.1-173.3 & $<0.0001^{* *}$ \\
\hline Weight (kg) & 58.1 & 9.8 & $42.0-84.2$ & 64.7 & 9.4 & $49.6-84.2$ & 52.3 & 5.5 & $42.0-63.0$ & $<0.0001^{* *}$ \\
\hline Body mass index $\left(\mathrm{kg} / \mathrm{m}^{2}\right)$ & 20.7 & 2.3 & $17.1-28.2$ & 21.2 & 2.7 & $17.1-28.2$ & 20.3 & 1.9 & $17.5-24.5$ & 0.1445 \\
\hline Body fat (\%) & 22.0 & 7.6 & $7.9-36.0$ & 15.9 & 5.4 & $7.9-28.8$ & 27.5 & 4.2 & $20.3-36.0$ & $<0.0001^{* *}$ \\
\hline
\end{tabular}

Data are presented as the means with standard deviation (SD).

Means are statistically different at $P<0.05$.

"Body mass index: underweight, $<18.5 \mathrm{~kg} / \mathrm{m}^{2}$; normal weight, $18.5-24.9 \mathrm{~kg} / \mathrm{m}^{2}$; overweight, $25-29.9 \mathrm{~kg} / \mathrm{m}^{2} ;$ obese, $\geq 30$.

${ }^{\#}$ Statistical difference between male and female subjects using Student's t-test or Welch's t-test.

$* * P<0.01$. 
Table 2. Food preference in male and female subjects.

\begin{tabular}{|c|c|c|c|c|c|c|}
\hline & & \multicolumn{2}{|c|}{$\begin{array}{c}\text { Men } \\
(n=25)\end{array}$} & \multicolumn{2}{|c|}{$\begin{array}{l}\text { Women } \\
(n=28)\end{array}$} & \multirow[b]{2}{*}{$P$ value } \\
\hline & & Mean & SD & Mean & SD & \\
\hline \multirow[t]{6}{*}{ Sweet food } & Azuki-bean jelly (Yokan) & 3.52 & 0.82 & 3.46 & 1.29 & 0.8506 \\
\hline & Steamed bean-jam bun (Manju) & 3.72 & 0.74 & 3.82 & 1.02 & 0.6832 \\
\hline & Candy & 3.40 & 0.87 & 3.00 & 1.05 & 0.1402 \\
\hline & Ice cream & 4.32 & 0.69 & 4.07 & 1.21 & 0.3586 \\
\hline & Chocolate & 3.92 & 0.95 & 4.11 & 1.20 & 0.5352 \\
\hline & $\begin{array}{l}\text { Strawberry sponge cake (Japanese style } \\
\text { shortcake) }\end{array}$ & 3.76 & 0.93 & 3.79 & 1.26 & 0.9335 \\
\hline \multirow[t]{7}{*}{ Salty food } & Potato chips & 3.92 & 0.91 & 3.71 & 1.21 & 0.4922 \\
\hline & Salted squids (Ika shiokara) & 3.00 & 1.35 & 3.29 & 1.44 & 0.4611 \\
\hline & Salted kelp (Shio kombu) & 3.04 & 1.10 & 3.43 & 1.20 & 0.2263 \\
\hline & Pickled vegetables (Tsukemono) & 3.28 & 0.98 & 3.57 & 1.20 & 0.3409 \\
\hline & Salted cod roe (Tarako) & 3.36 & 1.15 & 3.79 & 1.50 & 0.2559 \\
\hline & Salted salmon & 3.84 & 0.85 & 3.86 & 1.15 & 0.9514 \\
\hline & Miso soup (Misoshiru) & 4.08 & 0.81 & 4.32 & 0.94 & 0.3262 \\
\hline \multirow[t]{6}{*}{ Sour food } & Japanese orange (Mikan) & 4.40 & 0.76 & 4.32 & 1.16 & 0.7695 \\
\hline & Hassaku orange & 3.76 & 0.93 & 3.68 & 1.39 & 0.8010 \\
\hline & Pickled Japanese plum (Umeboshi) & 3.48 & 1.12 & 3.36 & 1.50 & 0.7391 \\
\hline & Yogurt & 4.00 & 0.82 & 4.18 & 1.19 & 0.5315 \\
\hline & Lemon & 3.20 & 1.00 & 3.36 & 1.13 & 0.5960 \\
\hline & Grapefruit & 3.52 & 1.00 & 3.61 & 1.40 & 0.7975 \\
\hline \multirow[t]{5}{*}{ Bitter food } & Celery & 2.40 & 0.96 & 2.61 & 1.50 & 0.5476 \\
\hline & Tea & 4.36 & 0.64 & 4.36 & 0.91 & 0.9896 \\
\hline & Green pepper & 3.68 & 0.85 & 3.46 & 1.14 & 0.4429 \\
\hline & Parsley & 3.08 & 0.95 & 2.71 & 1.33 & 0.2604 \\
\hline & Coffee & 3.80 & 1.19 & 3.46 & 1.23 & 0.3190 \\
\hline
\end{tabular}

Data are presented as the means with standard deviation (SD).

Means are statistically different at $P<0.05$.

"Statistical difference between male and female subjects using Student's t-test or Welch's t-test.

Men

Women

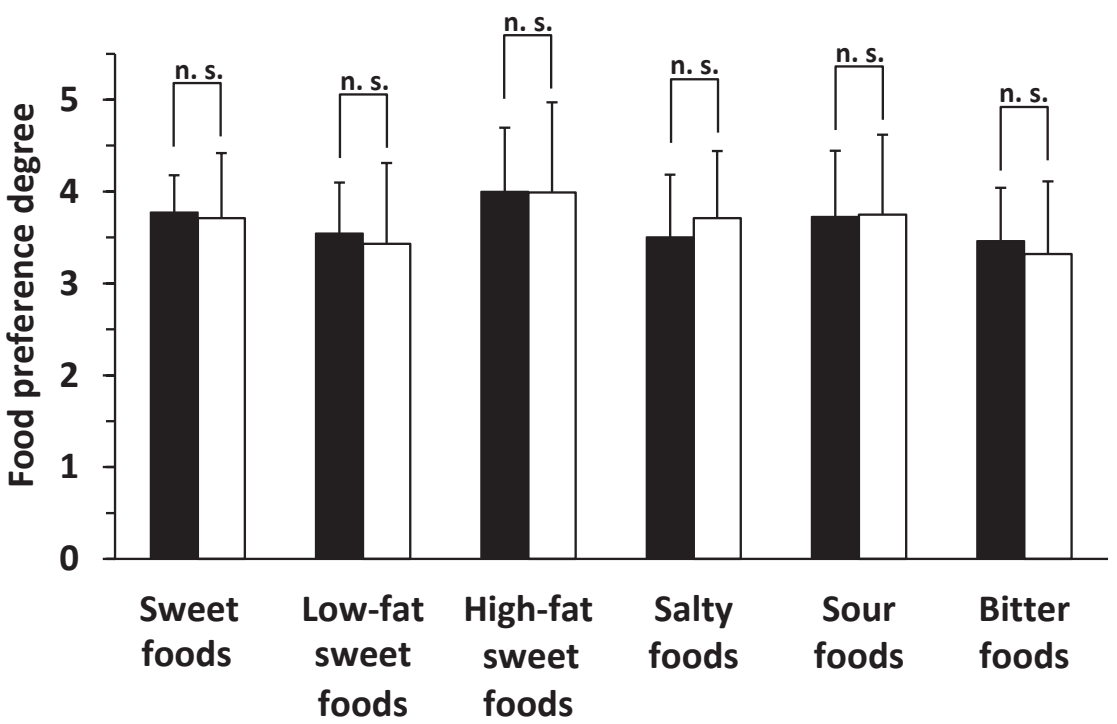

Fig. 1. Comparison of basic taste preference degrees between the two sex subgroups.

To determine preferences for basic tastes with the self-reported questionnaire, subjects provided a rating for their taste preference degree for a variety of tastants including four basic tastes (bitter, sour, salty, and sweet) on a scale of 1-5 as presented in Table 2, and as follows: scale 1, dislike very much; scale 2, dislike moderately; scale 3, neither like nor dislike; scale 4, like moderately; scale 5, like very much. The average preference degrees for each basic food taste were subsequently compared between men and women subgroups $(n=53)$. No significant differences in average taste preferences between males $(n=25)$ and females $(n=28)$ were identified based on a Student's t-test or Welch's t-test, for each indicated tastant. The six sweet foods listed in the self-reported questionnaires were then divided into two subgroups (high-fat sweet foods [ice cream, chocolate, and strawberry sponge cake] and low-fat sweet foods [yokan, manju, and candy]) in accordance with the content of general fat.

n.s., not significant. 
Table 3. Genotype frequencies of ADRB3 Trp64Arg (T/C) polymorphism in male and female subjects.

\begin{tabular}{|c|c|c|c|c|c|c|c|c|c|c|}
\hline \multirow{2}{*}{ SNP } & \multicolumn{5}{|c|}{ Men $(n=25)$} & \multicolumn{5}{|c|}{ Women $(n=28)$} \\
\hline & \multicolumn{3}{|c|}{ Ratio of genotypes } & \multicolumn{2}{|c|}{ Chi-square test } & \multicolumn{3}{|c|}{ Ratio of genotypes } & \multicolumn{2}{|c|}{ Chi-square test } \\
\hline \multirow{2}{*}{ 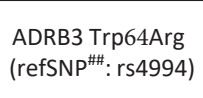 } & $\begin{array}{c}\mathrm{TT} \\
\text { (Trp64Trp) }\end{array}$ & $\begin{array}{c}\text { TC } \\
\text { (Trp64Arg) }\end{array}$ & $\begin{array}{c}C \mathrm{CC} \\
\text { (Arg64Arg) }\end{array}$ & $x^{2}$ & $P$ value $\#$ & $\begin{array}{c}\mathrm{TT} \\
\text { (Trp64Trp) }\end{array}$ & $\begin{array}{c}\text { TC } \\
\text { (Trp64Arg) }\end{array}$ & $\begin{array}{c}C \mathrm{CC} \\
\text { (Arg64Arg) }\end{array}$ & $x^{2}$ & $P$ value \\
\hline & $n=21(84.0)$ & $n=3(12.0)$ & $n=1(4.0)$ & 11.111 & $0.0039^{* *}$ & $n=18(64.3)$ & $n=10(35.7)$ & $n=0(0)$ & 4.668 & 0.097 \\
\hline
\end{tabular}

Values in parentheses are percentage of subjects.

The Hardy-Weinberg equilibrium and chi-square test were used to measure whether the observed genotype frequencies in subjects differ from the frequencies predicted by the equilibrium. As indicated, a significant difference was detected between them in male subjects, but not in female subjects.

Replacement of the thymine $(\mathrm{T})$ in the 190th position to cytosine (C) changes the 64th amino acid tryptophan (Trp) into an arginine (Arg) residue in the first intracellular loop of the human beta3-adrenergic receptor (ADRB3).

\#Significant difference was defined as $P<0.05$.

\#For each SNP, the reference SNP number (RefSNP) is given where available in the public database.

$* * P<0.01$.

SNP, single-nucleotide polymorphism.

Table 4. The effect of ADRB3 Trp64Arg (T/C) polymorphism on body mass index and body fat" in female subjects.

\begin{tabular}{|c|c|c|c|c|c|c|c|}
\hline & \multicolumn{3}{|c|}{$\begin{array}{c}\text { TT (Trp64Trp) } \\
(n=18)\end{array}$} & \multicolumn{3}{|c|}{$\begin{array}{c}\text { TC (Trp64Arg })^{\# \# \#} \\
(n=10)\end{array}$} & \multirow[t]{2}{*}{$P$ value $\#$} \\
\hline & Mean & SD & Range & Mean & SD & Range & \\
\hline Body mass index $\left(\mathrm{kg} / \mathrm{m}^{2}\right)$ & 20.3 & 1.9 & $17.5-23.2$ & 20.1 & 1.9 & $18.4-24.5$ & 0.7420 \\
\hline Body fat (\%) & 27.8 & 4.4 & 20.3-33.5 & 27.1 & 4.1 & $21.4-36.0$ & 0.6753 \\
\hline
\end{tabular}

Data are presented as the means with standard deviation (SD).

Means are statistically different at $P<0.05$.

Replacement of the thymine (T) in the 190th position to cytosine (C) changes the 64th amino acid tryptophan (Trp) into an arginine (Arg) residue in the first intracellular loop of the human beta3-adrenergic receptor (ADRB3).

"Body mass index: underweight, $<18.5 \mathrm{~kg} / \mathrm{m}^{2}$; normal weight, $18.5-24.9 \mathrm{~kg} / \mathrm{m}^{2}$; overweight, $25-29.9 \mathrm{~kg} / \mathrm{m}^{2} ;$ obese, $\geq 30$.

\#Differences between subjects with the TT (Trp64Trp) and TC (Trp64Arg) genotypes of ADRB3, as evaluated using Student's t-test.

\#\#) Female subjects with the CC (Arg64Arg) genotype of ADRB3: $n=0$.

equilibrium $(P>0.05$; Table 3$)$. Consequently, we divided all female subjects into two subgroups: subject with TT genotype (wild-type (WT) subgroup, $n=18$ ) and those with TC genotype (heterozygous subgroup, $n=10$ ). To examine the effect of the ADRB3 Trp64Arg (T/C) substitution on BMI and body fat, we compared average values between the two subgroups. As shown in Table 4, no significant difference was observed in average BMI or body fat between WT and heterozygous subgroups $(P>0.05)$.

To investigate the relationship between the ADRB3 Trp64Arg (T/C) polymorphism and the self-recognitions of taste preferences (bitter, sour, salty, and sweet), we used the prepared self-reported questionnaires. As shown in Table 5, there were significant increases in preference for only ice cream $(P<0.05)$, strawberry sponge cake [Japanese style shortcake] $(P<0.05)$, and Hassaku orange $(P<0.05)$ in the heterozygous subgroup. In addition, based on the average extent of preference for each basic tastant (bitter, sour, salty, or sweet), no significant increase in food preference was observed in the heterozygous subgroup ( $P>0.05$; Fig. 2$)$. However, among the six sweet foods included in the questionnaire, the average degree of preference for the three high-fat sweet foods, but not the three low-fat sweet foods, was significantly enhanced in the heterozygous subgroup compared to that in the WT group $(P<0.05$; Fig. 2$)$.
Finally, to investigate the relationship between the ADRB3 Trp64Arg (T/C) polymorphism and the self-recognition of taste preferences for greasy (high-fat) foods among the subjects, we focused on a specific question included in the self-reported questionnaires (Table 6), which was also used in a previous study (Asano et al. 2016). As shown in Table 6 and Fig. 3A and B, the preference degree for greasy foods largely differed among subjects, although no subject highly disliked greasy foods. However, the percentage of subjects who highly liked greasy foods tended to be substantially larger in the heterozygous subgroup than in the WT subgroup (Table 6 and Fig. 3A and B). Moreover, the average preference degree for greasy foods was not significantly different between the two genotype groups for all subjects $(P>0.05$; Fig. $3 C)$. However, when all subjects were divided into two subject classes based on their like or dislike of greasy foods (former class, $n=16$; latter class, $n=12$ ), the average preference degree for greasy foods in the heterozygous subgroup of the class who liked high-fat foods $(n=5)$ was significantly higher than that in the WT subgroup of the same class $(n=$ $11 ; P<0.05$; Fig. 3C).

\section{Discussion}

With regard to ADRB3, which plays a pivotal role in 
Table 5. Food preference in female subjects with the TT (Trp64Trp) and TC (Trp64Arg) genotypes of ADRB3.

\begin{tabular}{|c|c|c|c|c|c|c|}
\hline & & \multicolumn{2}{|c|}{$\begin{array}{l}\text { TT (Trp64Trp) } \\
(n=18)\end{array}$} & \multicolumn{2}{|c|}{$\begin{array}{c}\text { TC (Trp64Arg) } \\
(n=10)\end{array}$} & \multirow[b]{2}{*}{$P$ value ${ }^{\#}$} \\
\hline & & Mean & SD & Mean & SD & \\
\hline \multirow[t]{6}{*}{ Sweet food } & Azuki-bean jelly (Yokan) & 3.50 & 1.25 & 3.40 & 1.43 & 0.8485 \\
\hline & Steamed bean-jam bun (Manju) & 3.83 & 1.04 & 3.80 & 1.03 & 0.9358 \\
\hline & Candy & 2.83 & 1.15 & 3.30 & 0.82 & 0.2696 \\
\hline & Ice cream & 3.72 & 1.32 & 4.70 & 0.67 & $0.0155^{*}$ \\
\hline & Chocolate & 3.94 & 1.26 & 4.40 & 1.07 & 0.3440 \\
\hline & $\begin{array}{l}\text { Strawberry sponge cake (Japanese style } \\
\text { shortcake) }\end{array}$ & 3.39 & 1.33 & 4.50 & 0.71 & $0.0220^{*}$ \\
\hline \multirow[t]{7}{*}{ Salty food } & Potato chips & 3.78 & 1.40 & 3.60 & 0.84 & 0.7176 \\
\hline & Salted squids (Ika shiokara) & 3.50 & 1.20 & 2.90 & 1.79 & 0.2982 \\
\hline & Salted kelp (Shio kombu) & 3.44 & 1.20 & 3.40 & 1.26 & 0.9273 \\
\hline & Pickled vegetables (Tsukemono) & 3.61 & 1.24 & 3.50 & 1.18 & 0.8194 \\
\hline & Salted cod roe (Tarako) & 3.83 & 1.58 & 3.70 & 1.42 & 0.8265 \\
\hline & Salted salmon & 3.72 & 1.18 & 4.10 & 1.10 & 0.4133 \\
\hline & Miso soup (Misoshiru) & 4.22 & 1.11 & 4.50 & 0.53 & 0.3801 \\
\hline \multirow[t]{6}{*}{ Sour food } & Japanese orange (Mikan) & 4.11 & 1.32 & 4.70 & 0.67 & 0.1313 \\
\hline & Hassaku orange & 3.28 & 1.49 & 4.40 & 0.84 & $0.0379^{*}$ \\
\hline & Pickled Japanese plum (Umeboshi) & 3.39 & 1.58 & 3.30 & 1.42 & 0.8836 \\
\hline & Yogurt & 3.94 & 1.35 & 4.10 & 0.70 & 0.1025 \\
\hline & Lemon & 3.50 & 1.20 & 3.10 & 0.99 & 0.3791 \\
\hline & Grapefruit & 3.33 & 1.53 & 4.10 & 0.99 & 0.1682 \\
\hline \multirow[t]{5}{*}{ Bitter food } & Celery & 2.72 & 1.27 & 2.40 & 1.90 & 0.5953 \\
\hline & Tea & 4.22 & 1.06 & 4.60 & 0.52 & 0.2169 \\
\hline & Green pepper & 3.61 & 0.98 & 3.20 & 1.40 & 0.3696 \\
\hline & Parsley & 2.67 & 1.19 & 2.80 & 1.62 & 0.8047 \\
\hline & Coffee & 3.17 & 1.20 & 4.00 & 1.15 & 0.0862 \\
\hline
\end{tabular}

Data are presented as the means with standard deviation (SD). Means are statistically different at $P<0.05$.

Replacement of the thymine $(\mathrm{T})$ in the 190th position to cytosine $(\mathrm{C})$ changes the 64th amino acid tryptophan (Trp) into an arginine (Arg) residue in the first intracellular loop of the human beta3-adrenergic receptor (ADRB3).

\#Statistical difference between subjects with TT (Trp64Trp) and TC (Trp64Arg) genotypes of ADRB3 using Student's t-test or Welch's t-test.

\#Female subjects with the CC (Arg64Arg) genotype of ADRB3: $n=0$.

$* P<0.05$.

the regulation of lipolysis and thermogenesis in the white and brown adipose tissues of humans and rodents (Emorine et al. 1989; Nagase et al. 1996), screening studies have shown that the Trp64Arg polymorphism is present in most global populations (Yoshida and Sakane 1999). The relatively higher mutant allelic frequency of thrifty SNPs including the Trp64Arg (T/C) polymorphism of ADRB3 in Mongoloids, as compared to that in Caucasoids (for detail, see the Introduction), was thought to be acquired from ancestors due to differences in traditional lifestyles including eating habits. Specifically, Mongoloids consumed mostly root vegetables and rice, and not a high-calorie, animal-based diet like the Caucasoids (Yanagisawa et al. 2001; Kagawa et al. 2002, 2003).

In the present study (all subjects being Japanese), consistent with previous findings (Yoshida and Sakane 1999), the ADRB3 Arg64 variant allelic frequency in female subjects was $17.9 \%$ (which was calculated based on the data from Table 3, which shows genotype frequencies of the ADRB3 Trp64Arg (T/C) polymorphism in the subjects). However, for unknown reasons, in male subjects, the
ADRB3 Arg64 allelic frequency was $10.0 \%$, which was lower than that of previous findings (Yoshida and Sakane 1999). In addition, the observed genotype frequencies of the Trp64Arg polymorphism of the ADRB3 gene in female subjects, but not male subjects, were in accordance with the Hardy-Weinberg equilibrium (Table 3), suggesting that the observed genotype frequencies in females, but not in males, represent those of the whole population. Therefore, in the present study, we decided to further analyze the effect of the Trp64Arg (T/C) substitution of $A D R B 3$ on the investigated taste preferences, using data only from female subjects. Further study is needed to precisely evaluate the effect of the Trp64Arg (T/C) substitution on taste preference among men.

The Trp64Arg (T/C) substitution of ADRB3 decreases ADRB3 function in adipocytes, as described in Introduction. It can, for example, subsequently reduce basal metabolic expenditure in individuals, which is followed by an increase in resistance to starvation (Yoshida and Sakane 1999; Li et al. 2018). However, to date, no study has analyzed the potential effect of this mutation on 


\section{TT (Trp64Trp) $\square$ TC (Trp64Arg)}

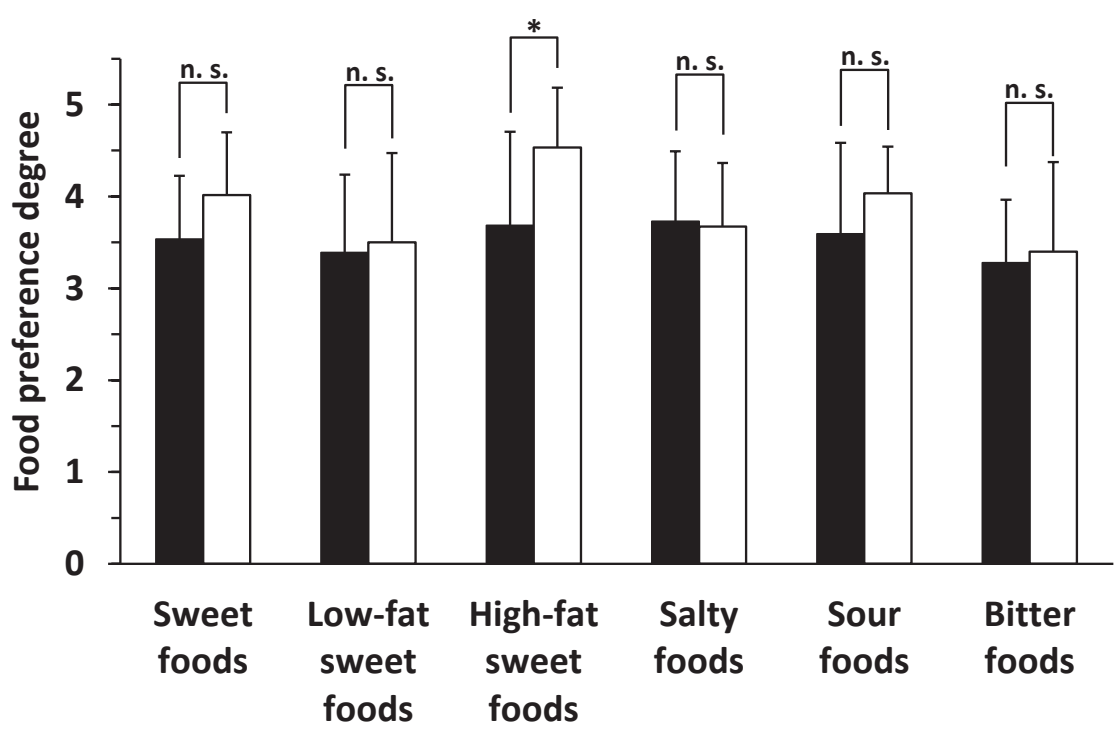

Fig. 2. Comparison of basic taste preference degrees between genotype subgroups of female subjects.

To determine preferences for basic tastes with the self-reported questionnaire, subjects provided a rating for their taste preference degree for a variety of tastants including four basic tastes (bitter, sour, salty, and sweet) on a scale of 1-5 as presented in Table 5, and as follows: scale 1, dislike very much; scale 2, dislike moderately; scale 3, neither like nor dislike; scale 4, like moderately; scale 5, like very much. The average preference degrees for each basic food taste were subsequently compared between the indicated genotype subgroups of female subjects. For the comparison of average taste preference between genotype subgroups (subjects with TT (Trp64Trp) genotype of ADRB3 (ADRB3 wild-type subgroup) and with TC (Trp64Arg) genotype of ADRB3 (ADRB3 heterozygous subgroup); $n=28$ ), significant differences in average taste preference degrees between the ADRB3 wild-type subgroup $(n=18)$ and the ADRB3 heterozygous subgroup $(n=10)$ genotype subgroups were identified by performing a Student's t-test or Welch's t-test, for each indicated tastant. The six sweet foods listed in the self-reported questionnaires were also divided into two subgroups (high-fat sweet foods [ice cream, chocolate, and strawberry sponge cake] and low-fat sweet foods [yokan, manju, and candy]) in accordance with the content of general fat.

$* P<0.05$.

n.s., not significant.

Table 6. The response to a question on greasy food preference in female subjects with the TT (Trp64Trp) and TC (Trp64Arg) genotypes of $A D R B 3$.

\begin{tabular}{|c|c|c|c|c|c|c|}
\hline \multirow{2}{*}{\multicolumn{2}{|c|}{ Question: Do you like greasy foods? }} & \multirow[t]{2}{*}{ [score] } & \multicolumn{2}{|c|}{$\begin{array}{l}\text { genotype: TT (Trp64Trp) } \\
\qquad(n=18)\end{array}$} & \multicolumn{2}{|c|}{$\begin{array}{l}\text { genotype: TC (Trp64Arg) } \\
\qquad(n=10)\end{array}$} \\
\hline & & & $n$ & percentage (\%) & $n$ & percentage (\%) \\
\hline Scale 1. & I like them very much. & 4 & 1 & 5.6 & 3 & 30.0 \\
\hline Scale 2. & I like them moderately. & 3 & 10 & 55.6 & 2 & 20.0 \\
\hline Scale 3. & I dislike them moderately. & 2 & 7 & 38.9 & 5 & 50.0 \\
\hline Scale 4. & I dislike them very much. & 1 & 0 & 0.0 & 0 & 0.0 \\
\hline
\end{tabular}

The question included in the self-reported questionnaire is for evaluating the greasy food preference degree in each subject.

Replacement of the thymine (T) in the 190th position to cytosine (C) changes the 64th amino acid tryptophan (Trp) into an arginine (Arg) residue in the first intracellular loop of the human beta3-adrenergic receptor (ADRB3).

\#Female subjects with the CC (Arg64Arg) genotype of ADRB3: $n=0$.

self-recognition of basic and high-fat taste preference. Here, we characterized the association between this mutation and the self-recognition of various taste food preferences in healthy young Japanese women. Our results clearly showed that there is a specific association between the heterozygous $A D R B 3 \operatorname{Trp} 64 \operatorname{Arg}(\mathrm{T} / \mathrm{C})$ substitution and an increased degree of high-fat sweet food preference, but not low-fat food preference, among female subjects (Fig. 2). Other investigated food preferences for basic tastes (bitter, sour, and salty tastes) were not changed by this alteration (Fig. 2). We also clearly showed that the degree of greasy food preference was significantly increased by the Trp64Arg (T/C) substitution, but only in subjects who liked greasy foods (Fig. 3).

The genetically-enhanced high-fat food preference associated with the Trp64Arg (T/C) substitution in the present study (Tables 5 and 6) might be evolutionarily useful to overcome starvation with food shortages, because selecting 
A

\section{TT (Trp64Trp) genotype}

$38.9 \%$

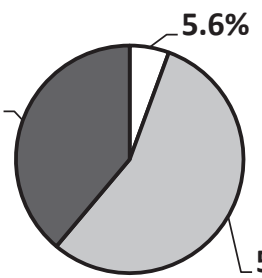

$55.6 \%$

B

\section{TC (Trp64Arg) genotype}

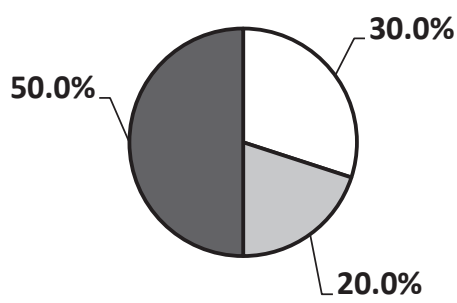

口Scale 1 पScale 2 口Scale 3

\section{口Scale 1 口Scale 2 口Scale 3}

\section{C}

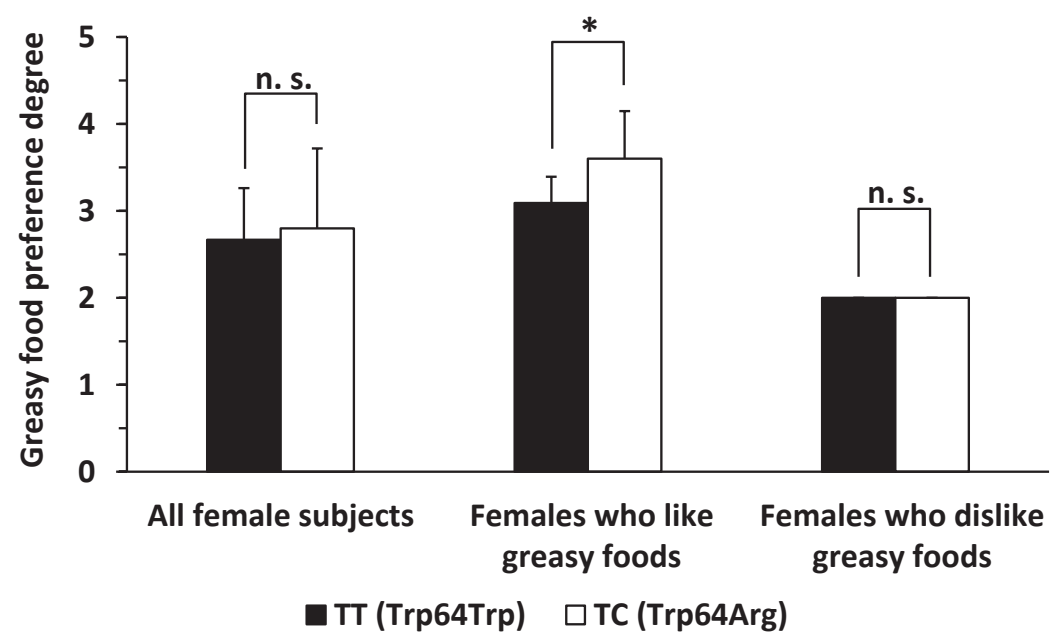

Fig. 3. Comparison of greasy food preference degrees between genotype subgroups of female subjects.

Using the self-reported questionnaire for taste preference, subjects provided a rating for their preference degree of greasy foods on a scale of 1-4 as presented in Table 6, and as follows: scale 1, like very much (score: 4); scale 2, like moderately (score: 3); scale 3, dislike moderately (score: 2 ); scale 4, dislike very much (score: 1 ). The percentage of female subjects who selected each value and the average degrees of preference were evaluated and compared between the indicated genotype subgroups. (A) Pie chart showing the percentage of individuals who selected each number (scale: 1-4) among subjects with the TT (Trp64Trp) genotype of the ADRB3 gene (ADRB3 wild-type subgroup). No subject selected 4 in the self-reported questionnaire. (B) Pie chart showing the percentage of individuals who selected each number (scale: 1-4) among subjects with the TC (Trp64Arg) genotype of the ADRB3 gene (ADRB3 heterozygous subgroup). Again, no subject selected 4 in the self-reported questionnaire. (C) Comparison of average greasy food preference degree between the two genotype subgroups (the ADRB3 wild-type subgroup and the ADRB3 heterozygous subgroup) for all female subjects $(n=28)$, a class of subjects who liked greasy foods $(n=16)$, and the other class of subjects who disliked greasy foods $(n=12)$. Significant differences were observed in average greasy food preference degree between the two genotype subgroups (the ADRB3 wild-type subgroup, $n=11$ and the ADRB3 heterozygous subgroup, $n=5$ ) for the class of subjects who liked greasy foods. No difference was observed in all subjects (the ADRB3 wild-type subgroup, $n=18$ and the ADRB3 heterozygous subgroup, $n=10$ ) or the other class of subjects who disliked greasy foods (the ADRB3 wild-type subgroup, $n=7$ and the ADRB3 heterozygous subgroup, $n=5$ ). Significant differences in average taste preference degrees between the ADRB3 wild-type subgroup and the ADRB3 heterozygous subgroup were identified by performing a Student's t-test or Welch's t-test. $* P<0.05$. n.s., not significant.

higher-fat foods would increase caloric intake, enhancing the possibility of survival. However, the precise mechanism through which the heterozygous Trp64Arg (T/C) status affects taste preference was not elucidated in the present study. In relation to this point, it should be noted that ADRB3 is an essential mediator of fat metabolism in the body. Thus, a possible reason for the high-fat food preference associated with the ADRB3 Arg64 variant allele might be the reduction in noradrenalin-dependent lipolysis activity with this variant.

More specifically, such reduced receptor activity, followed by decreased fat metabolism in white and brown adi- 
pose tissue in humans, might affect the principal pathways that regulate food intake in the brain such as pathways that mediate (i) metabolic homeostasis and (ii) food reward, via an unknown mechanism. In addition, we also consider another possibility, specifically that the change in receptor activity might affect the perception of fat in the oral cavity through an unknown mechanism. In this context, it is interesting that Asano et al. (2016) previously reported no significant association between oral fat sensitivity and the degree of greasy food preference in healthy young adults.

For example, with respect to other genes, altered calorie-dense food preferences induced by gene mutations in the fat mass and obesity-associated (FTO) gene and Tolllike receptor 4 (TLR4, which encodes a transmembrane protein that belongs to the Toll-like receptor family) gene have been reported in humans and mice, respectively (Brunkwall et al. 2013; Camandola and Mattson 2017). In these reports, it was suggested that the FTO polymorphism (reference SNP number: rs9939609; hypothalamic FTO is associated with the regulation of energy intake) and the deletion of TLR 4 might be associated with altered hypothalamus function (a center that mediates food intake in the brain) and the altered expression of proteins in the tongue epithelium that are related to taste perception (including sweet, umami, and fat tastes), respectively. Therefore, these results imply that the effects of gene mutations on high-calorie food preference would be helpful to understand the exact mechanism through which the ADRB3 Trp64Arg variant increases high-fat preference in humans.

Regarding the effect of the ADRB3 Trp64Arg (T/C) substitution on BMI, results in related reports have been conflicting; however, nonetheless, this alteration is associated with increased visceral fat and an increased risk of NIDDM. Initial studies reported that the ADRB3 Trp64Arg (T/C) substitution is associated with increased weight gain in the French (Clément et al. 1995). However, our results and several other reports failed to show such changes in BMI with the Trp64Arg substitution (Kim-Motoyama et al. 1997; Nagase et al. 1997; Sakane et al. 1997; Masuo et al. 2005), despite the fact that both decreased basal metabolic expenditure and increased high-fat preferences (the latter first shown in the present study) can induce weight gain (Ravussin et al. 1988; Gaillard et al. 2008). The possible reasons as to why no differences were observed in the present study are as follows: (i) the age of subjects was limited to young adults (in their 20s and 30s). Therefore, basal metabolic expenditure was relatively high compared to that at older ages. This might compensate for the difference in metabolic expenditure or fatty taste preference induced by the Trp64Arg substitution. (ii) Obesity might be induced by a complex combination of various related factors. Thus, increased energy expenditure accompanied by exercise might compensate for the differences in metabolic expenditure or fatty taste preference induced by the alteration in ADRB3.

It should also be noted that the $A D R B 3 \operatorname{Trp} 64 \mathrm{Arg}(\mathrm{T} / \mathrm{C})$ substitution had a significant effect on high-fat preferences in young adults. Thus, the novel findings of the present study could be useful for the early prevention of severe obesity and its complications in individuals harboring the Arg64 variant allele(s) in ADRB3.

In relation to the aforementioned human studies on the ADRB3 Trp64Arg (T/C) polymorphism, an animal study using gene knockout mice lacking functional ADRB3 already showed interesting results; specifically, the mice had only a slight increase in body fat, but otherwise, they appeared normal (Susulic et al. 1995), which supports the idea that mammals have certain adaptation mechanisms that can compensate for the substantial reduction or deletion of functional ADRB3 regarding fat metabolism, to some extent. In addition, the knockout mice were completely resistant to the ability of an ADRB3 agonist (CL-316243, a low molecular weight compound) to reduce food intake as a result of ADRB3 activation. Furthermore, the effect on food intake was completely rescued with the transgenic expression of normal ADRB3 in white and brown adipocytes (Susulic et al. 1995; Grujic et al. 1997), suggesting that functional ADRB3 could be involved in the physiological pathways that regulate intrinsic food intake.

In contrast, Sasaki et al. (2013) reported different results regarding fat preference in a human study, compared to the results of the present study. To evaluate food preferences based on nutrient intake, Sasaki and coworkers estimated the intake of various food groups in young adult Japanese women; in other words, they estimated the temporal status of food preference among the subjects when the participants had eaten the foods (Sasaki et al. 2013). Based on the data, they showed that there was no significant difference in fat preference between the ADRB3 Trp64Arg (T/ C) polymorphism genotypes. Although we have no logical explanation for this discrepancy, as a possibility, these different results might partially be related to the different methods employed to evaluate fat preference itself (we evaluated self-recognition of average, but not temporal, food preferences with hedonic scales in the present study). It should also be noted that there is a possibility that the estimated amount of fat intake, which is a useful index to evaluate fat preference, might not always linearly reflect the self-recognition of average fat preference degree in individuals, because factors other than temporal status of food preference might also participate in the determination of food intake to maintain an appropriate body weight in humans. Further study will be necessary to clarify the interactions between fat preference and $A D R B 3$ genotypes in humans.

The present study is subject to certain limitations that are worth noting. The primary limitation is the small subject population, which might have resulted in low statistical power; however, this population was adequate to obtain significant correlations between taste preferences and the ADRB3 Trp64Arg (T/C) polymorphism in women. The second concerns the self-reported style of the questionnaire, 
which might have included individual biases that could have altered the results. It should also be pointed out that our research group prepared the questions shown in Tables 2,5 , and 6 in the Japanese language. Specifically, the subjects in the present study answered the Japanese language version of the questionnaire, but not the translated English language version presented in the tables. The third is the effect of sex differences on taste preference. Sex might be a relevant variable that has been poorly analyzed regarding taste perception and preference (Wright 1973; Verma et al. 2005; Barragán et al. 2018). In contrast, there have been reports showing the hormonal influence on taste preferences (Martin and Sollars 2017). Thus, although we found no apparent difference between the basic taste preferences of males and females, as shown in Table 2 and Fig. 1, we decided not to analyze the data for men and women in an integrated manner. In this context, the degree of taste preference toward each food for the subjects queried in the present study was averaged, but the temporal status was not included. Therefore, in the present study, we did not collect data on the hormonal status of female subjects in the selfreported questionnaire of the present study and did not further divide the women into subgroups based on hormonal status or other relevant parameters. Nonetheless, further study regarding fat preference with respect to hormonal status in women might be considerably valuable to more precisely comprehend the relationship between the ADRB3 Trp64Arg (T/C) polymorphism and fat preference. Last, the subjects in the present study were non-smoking, nonmedicated Japanese young adults of good health condition, which might not precisely represent general populations.

The causative factors of obesity are complex and diverse and include genetic factors in addition to physiologic and environmental factors (Torres and Nowson 2007; Tanaka et al. 2018). A preference for high-fat foods is only one factor that causes obesity, and it might not be a major one. Despite this, the ingestion of dietary fat is mainly associated with body weight control (Bray et al. 2004; Astrup 2005; Haryono et al. 2014). This suggests that an inappropriately enhanced preference for fat might have effects on obesity risk by influencing behaviors associated with food intake (Tanaka et al. 2018). Therefore, revealing how factors that mediate fatty food preference are linked to human body weight maintenance would be highly valuable.

In the present study, we concentrated on the biological relationship between taste preferences and the Trp64Arg (T/ C) polymorphism of $A D R B 3$ in young Japanese women who were healthy. It was determined by this research that a high-fat sweet food preference, but not the other basic taste preferences (including low-fat sweet food), was specifically associated with this polymorphism by evaluating food preferences based on self-recognition. Accordingly, we also found that self-recognition of a greasy food preference was increased with this alteration among subjects who like greasy foods. These findings are important, especially for future individualized medicine, as an increased preference for high-fat foods, which are representative high-calorie foods, might result in inappropriate eating habits such as over-eating. This might eventually increase the risk of severe obesity, diabetes, or other lifestyle-related disorders in humans. Taken together, our results suggest that the ADRB3 Trp64Arg (T/C) polymorphism might have a specific correlation with the self-recognition of high-fat food preference in healthy young adults through an unidentified mechanism. Additional studies on the association between this polymorphism and high-fat food preference would be considerably valuable to understand the regulatory mechanisms supporting such food preference and to develop tools for personalized medicine to analyze individual differences in fat preference. This could contribute to the evaluation of ADRB3-related dysfunctions in fatty taste preference, which could be exploited to prevent or manage obesity caused by overeating.

\section{Acknowledgments}

We are grateful to Messrs. Toru Atsumi, Syutaro Sato, Drs. Yuki Watanabe, Kazushi Hirosawa, and Prof. Minoru Wakamori for advice, helpful discussion, and technical assistance regarding this work.

\section{Conflict of Interest}

The authors declare no conflict of interest.

\section{References}

Adachi, S., Endo, Y., Mizushige, T., Tsuzuki, S., Matsumura, S., Inoue, K. \& Fushiki, T. (2013) Increased levels of extracellular dopamine in the nucleus accumbens and amygdala of rats by ingesting a low concentration of a long-chain fatty acid. Biosci. Biotechnol. Biochem., 77, 2175-2180.

Asano, M., Hong, G., Matsuyama, Y., Wang, W., Izumi, S., Izumi, M., Toda, T. \& Kudo, T.A. (2016) Association of oral fat sensitivity with body mass index, taste preference, and eating habits in healthy Japanese young adults. Tohoku J. Exp. Med., 238, 93-103.

Astrup, A. (2005) The role of dietary fat in obesity. Semin. Vasc. Med., 5, 40-47.

Barragán, R., Coltell, O., Portolés, O., Asensio, E.M., Sorlí, J.V., Ortega-Azorín, C., González, J.I., Sáiz, C., Fernández-Carrión, R., Ordovas, J.M. \& Corella, D. (2018) Bitter, sweet, salty, sour and umami taste perception decreases with age: sex-specific analysis, modulation by genetic variants and tastepreference associations in 18 to 80 year-old subjects. Nutrients, 10, 1539.

Bjerregaard, P., Young, T.K. \& Hegele, R.A. (2003) Low incidence of cardiovascular disease among the Inuit: what is the evidence? Atherosclerosis, 166, 351-357.

Bray, G.A., Paeratakul, S. \& Popkin, B.M. (2004) Dietary fat and obesity: a review of animal, clinical and epidemiological studies. Physiol. Behav., 83, 549-555.

Brunkwall, L., Ericson, U., Hellstrand, S., Gullberg, B., OrhoMelander, M. \& Sonestedt, E. (2013) Genetic variation in the fat mass and obesity-associated gene (FTO) in association with food preferences in healthy adults. Food Nutr. Res., 57.

Camandola, S. \& Mattson, M.P. (2017) Toll-like receptor 4 mediates fat, sugar, and umami taste preference and food intake and body weight regulation. Obesity (Silver Spring), 25, 1237-1245.

Cartoni, C., Yasumatsu, K., Ohkuri, T., Shigemura, N., Yoshida, R., Godinot, N., le Coutre, J., Ninomiya, Y. \& Damak, S. (2010) 
Taste preference for fatty acids is mediated by GPR 40 and GPR120. J. Neurosci., 30, 8376-8382.

Clément, K., Vaisse, C., Manning, B.S., Basdevant, A., Guy-Grand, B., Ruiz, J., Silver, K.D., Shuldiner, A.R., Froguel, P. \& Strosberg, A.D. (1995) Genetic variation in the beta 3-adrenergic receptor and an increased capacity to gain weight in patients with morbid obesity. N. Engl. J. Med., 333, 352-354.

Costanzo, A., Orellana, L., Nowson, C., Duesing, K. \& Keast, R. (2017) Fat taste sensitivity is associated with short-term and habitual fat intake. Nutrients, 9.

de Luis, D.A., Aller, R., Izaola, O., Gonzalez-Sagrado, M. \& Conde, R. (2008) Relation of Trp64Arg polymorphism of beta3-adrenoreceptor gene with cardiovascular risk factors in presurgical morbidly obese patients. Arch. Med. Res., 39, 791-795.

DiPatrizio, N.V. (2014) Is fat taste ready for primetime? Physiol. Behav., 136, 145-154.

Drewnowski, A. \& Greenwood, M.R. (1983) Cream and sugar: human preferences for high-fat foods. Physiol. Behav., 30, 629-633.

Emorine, L.J., Marullo, S., Briend-Sutren, M.M., Patey, G., Tate, K., Delavier-Klutchko, C. \& Strosberg, A.D. (1989) Molecular characterization of the human beta 3-adrenergic receptor. Science, 245, 1118-1121.

Fushiki, T. (2014) Why fat is so preferable: from oral fat detection to inducing reward in the brain. Biosci. Biotechnol. Biochem., 78, 363-369.

Gaillard, D., Passilly-Degrace, P. \& Besnard, P. (2008) Molecular mechanisms of fat preference and overeating. Ann. NY Acad. Sci., 1141, 163-175.

Grujic, D., Susulic, V.S., Harper, M.E., Himms-Hagen, J., Cunningham, B.A., Corkey, B.E. \& Lowell, B.B. (1997) Beta3-adrenergic receptors on white and brown adipocytes mediate beta3-selective agonist-induced effects on energy expenditure, insulin secretion, and food intake. A study using transgenic and gene knockout mice. J. Biol. Chem., 272, 17686-17693.

Haryono, R.Y., Sprajcer, M.A. \& Keast, R.S. (2014) Measuring oral fatty acid thresholds, fat perception, fatty food liking, and papillae density in humans. J. Vis. Exp., 88, e51236.

Hubert, H.B., Feinleib, M., McNamara, P.M. \& Castelli, W.P. (1983) Obesity as an independent risk factor for cardiovascular disease: a 26-year follow-up of participants in the Framingham Heart Study. Circulation, 67, 968-977.

Imaizumi, M., Takeda, M. \& Fushiki, T. (2000) Effects of oil intake in the conditioned place preference test in mice. Brain Res., 870, 150-156.

Janssen, S. \& Depoortere, I. (2013) Nutrient sensing in the gut: new roads to therapeutics? Trends Endocrinol. Metab., 24, 92-100.

Kagawa, Y., Dever, G.J., Otto, C.T., Charupoonphol, P., Supannatas, S., Yanagisawa, Y., Sakuma, M. \& Hasegawa, K. (2003) Single nucleotide polymorphism and lifestyle-related diseases in the Asia-Pacific region: comparative study in Okinawa, Palau and Thailand. Asia Pac. J. Public Health, 15 Suppl, S10-14.

Kagawa, Y., Yanagisawa, Y., Hasegawa, K., Suzuki, H., Yasuda, K., Kudo, H., Abe, M., Matsuda, S., Ishikawa, Y., Tsuchiya, N., Sato, A., Umetsu, K. \& Kagawa, Y. (2002) Single nucleotide polymorphisms of thrifty genes for energy metabolism: evolutionary origins and prospects for intervention to prevent obesity-related diseases. Biochem. Biophys. Res. Commun., 295, 207-222.

Keast, R.S.J. \& Costanzo, A. (2015) Is fat the sixth taste primary? Evidence and implications. Flavour, 4, 5.

Kim-Motoyama, H., Yasuda, K., Yamaguchi, T., Yamada, N., Katakura, T., Shuldiner, A.R., Akanuma, Y., Ohashi, Y., Yazaki, Y. \& Kadowaki, T. (1997) A mutation of the beta 3 -adrenergic receptor is associated with visceral obesity but decreased serum triglyceride. Diabetologia, 40, 469-472.

Kovesdy, C.P., Furth, S.L. \& Zoccali, C. (2017) Obesity and kidney disease: hidden consequences of the epidemic. Afr. J. Prim. Health Care Fam. Med., 9, e1-e3.

Li, Y.Y., Lu, X.Z., Wang, H., Zhou, Y.H., Yang, X.X., Geng, H.Y., Gong, G. \& Kim, H.J. (2018) ADRB3 gene Trp64Arg polymorphism and essential hypertension: a meta-analysis including 9,555 subjects. Front. Genet., 9, 106.

Martin, L.J. \& Sollars, S.I. (2017) Contributory role of sex differences in the variations of gustatory function. J. Neurosci. Res., 95, 594-603.

Martínez-Ruiz, N.R., Lopez-Diaz, J.A., Wall-Medrano, A., Jimenez-Castro, J.A. \& Angulo, O. (2014) Oral fat perception is related with body mass index, preference and consumption of high-fat foods. Physiol. Behav., 129, 36-42.

Masuo, K., Katsuya, T., Fu, Y., Rakugi, H., Ogihara, T. \& Tuck, M.L. (2005) Beta2- and beta3-adrenergic receptor polymorphisms are related to the onset of weight gain and blood pressure elevation over 5 years. Circulation, 111, 3429-3434.

Mattes, R.D. (2011) Accumulating evidence supports a taste component for free fatty acids in humans. Physiol. Behav., 104, 624-631.

Mizushige, T., Inoue, K. \& Fushiki, T. (2007) Why is fat so tasty? Chemical reception of fatty acid on the tongue. J. Nutr. Sci. Vitaminol. (Tokyo), 53, 1-4.

Morton, G.J., Cummings, D.E., Baskin, D.G., Barsh, G.S. \& Schwartz, M.W. (2006) Central nervous system control of food intake and body weight. Nature, 443, 289-295.

Murakami, N., Nakamura, Y., Nakajima, T., Sasakawa, Y., Nakakura-Ohshima, K., Murakami, T., Kurosawa, M., Iwase, Y., Murakami, D., Saitoh, I., Inada, E., Yamasaki, Y. \& Hayasaki, H. (2017) Oral feeding behavior during a whole meal. Dent. Oral Craniofac. Res., 4, 1-7.

Nagase, I., Yoshida, T., Kumamoto, K., Umekawa, T., Sakane, N., Nikami, H., Kawada, T. \& Saito, M. (1996) Expression of uncoupling protein in skeletal muscle and white fat of obese mice treated with thermogenic beta 3 -adrenergic agonist. $J$. Clin. Invest., 97, 2898-2904.

Nagase, T., Aoki, A., Yamamoto, M., Yasuda, H., Kado, S., Nishikawa, M., Kugai, N., Akatsu, T. \& Nagata, N. (1997) Lack of association between the Trp64 Arg mutation in the beta 3-adrenergic receptor gene and obesity in Japanese men: a longitudinal analysis. J. Clin. Endocrinol. Metab., 82, 12841287.

Ohmori, R. (2013) Comparisons of the taste sensitivity between three generations. Bull. Fac. Educ. Utsunomiya Univ., 63, 201-210

Pang, J., Xi, C., Huang, X., Cui, J., Gong, H. \& Zhang, T. (2016) Effects of excess energy intake on glucose and lipid metabolism in C57BL/6 mice. PLoS One, 11, e0146675.

Ravussin, E., Lillioja, S., Knowler, W.C., Christin, L., Freymond, D., Abbott, W.G., Boyce, V., Howard, B.V. \& Bogardus, C. (1988) Reduced rate of energy expenditure as a risk factor for body-weight gain. N. Engl. J. Med., 318, 467-472.

Rosenbaum, M., Leibel, R.L. \& Hirsch, J. (1997) Obesity. $N$. Engl. J. Med., 337, 396-407.

Sakane, N., Yoshida, T., Umekawa, T., Kondo, M., Sakai, Y. \& Takahashi, T. (1997) Beta 3-adrenergic-receptor polymorphism: a genetic marker for visceral fat obesity and the insulin resistance syndrome. Diabetologia, 40, 200-204.

Sasaki, M., Yamada, K., Namba, H., Yoshinaga, M., Du, D. \& Uehara, Y. (2013) Angiotensinogen gene polymorphisms and food-intake behavior in young, normal female subjects in Japan. Nutrition, 29, 60-65.

Satoh-Kuriwada, S., Kawai, M., Iikubo, M., Sekine-Hayakawa, Y., Shoji, N., Uneyama, H. \& Sasano, T. (2014) Development of an umami taste sensitivity test and its clinical use. PLoS One, 9, e95177.

Sipiläinen, R., Uusitupa, M., Heikkinen, S., Rissanen, A. \& 
Laakso, M. (1997) Polymorphism of the beta3-adrenergic receptor gene affects basal metabolic rate in obese Finns. Diabetes, 46, 77-80.

Stewart, J.E., Feinle-Bisset, C., Golding, M., Delahunty, C., Clifton, P.M. \& Keast, R.S. (2010) Oral sensitivity to fatty acids, food consumption and BMI in human subjects. $B r . J$. Nutr., 104, 145-152.

Stewart, J.E. \& Keast, R.S. (2012) Recent fat intake modulates fat taste sensitivity in lean and overweight subjects. Int. J. Obes. (Lond.), 36, 834-842.

Stewart, J.E., Newman, L.P. \& Keast, R.S. (2011) Oral sensitivity to oleic acid is associated with fat intake and body mass index. Clin. Nutr., 30, 838-844.

Strosberg, A.D. (1997) Structure and function of the beta 3-adrenergic receptor. Annu. Rev. Pharmacol. Toxicol., 37, 421-450.

Susulic, V.S., Frederich, R.C., Lawitts, J., Tozzo, E., Kahn, B.B., Harper, M.E., Himms-Hagen, J., Flier, J.S. \& Lowell, B.B. (1995) Targeted disruption of the beta 3-adrenergic receptor gene. J. Biol. Chem., 270, 29483-29492.

Takeuchi, S., Katoh, T., Yamauchi, T. \& Kuroda, Y. (2012) ADRB3 polymorphism associated with BMI gain in Japanese men. Exp. Diabetes Res., 2012, 973561.

Tanaka, T., Hong, G., Tominami, K. \& Kudo, T.A. (2018) Oral fat sensitivity is associated with social support for stress coping in young adult men. Tohoku J. Exp. Med., 244, 249-261.

Tchernof, A., Starling, R.D., Walston, J.D., Shuldiner, A.R., Dvorak, R.V., Silver, K., Matthews, D.E. \& Poehlman, E.T. (1999) Obesity-related phenotypes and the beta3-adrenoceptor gene variant in postmenopausal women. Diabetes, $\mathbf{4 8}$,
$1425-1428$.

Thomas, G.N., Tomlinson, B., Chan, J.C., Young, R.P. \& Critchley, J.A. (2000) The Trp64Arg polymorphism of the beta3-adrenergic receptor gene and obesity in Chinese subjects with components of the metabolic syndrome. Int. J. Obes. Relat. Metab. Disord., 24, 545-551.

Torres, S.J. \& Nowson, C.A. (2007) Relationship between stress, eating behavior, and obesity. Nutrition, 23, 887-894.

True, C., Arik, A., Lindsley, S., Kirigiti, M., Sullivan, E. \& Kievit, P. (2018) Early high-fat diet exposure causes dysregulation of the orexin and dopamine neuronal populations in nonhuman primates. Front. Endocrinol. (Lausanne), 9, 508.

Verma, P., Mahajan, K.K., Mittal, S. \& Ghildiyal, A. (2005) Salt preference across different phases of menstrual cycle. Indian J. Physiol. Pharmacol., 49, 99-102.

Wright, P. (1973) Menstrual cycle: effect on sweetness preferences in women. Horm. Behav., 4, 387-391.

Yanagisawa, Y., Hasegawa, K., Dever, G.J., Otto, C.T., Sakuma, M., Shibata, S., Miyagi, S., Kaneko, Y. \& Kagawa, Y. (2001) Uncoupling protein 3 and peroxisome proliferator-activated receptor gamma2 contribute to obesity and diabetes in palauans. Biochem. Biophys. Res. Commun., 281, 772-778.

Yoneda, T., Taka, Y., Okamura, M., Mizushige, T., Matsumura, S., Manabe, Y., Tsuzuki, S., Inoue, K. \& Fushiki, T. (2007) Reinforcing effect for corn oil stimulus was concentration dependent in an operant task in mice. Life Sci., 81, 1585-1592.

Yoshida, T. \& Sakane, N. (1999) Association between beta3-adrenoreceptor polymorphism with obesity and diabetes in Japan. Intern. Med., 38, 207-209. 